2016-02

Using competing models to evaluate the

role of environmental pressures in

ecommerce adoption by small and

medium sized travel agents in a

developing country

\author{
Abou-Shouk, Mohamed
}

http://hdl.handle.net/10026.1/16154

10.1016/j.tourman.2015.07.007

Tourism Management

Elsevier BV

All content in PEARL is protected by copyright law. Author manuscripts are made available in accordance with publisher policies. Please cite only the published version using the details provided on the item record or document. In the absence of an open licence (e.g. Creative Commons), permissions for further reuse of content should be sought from the publisher or author. 


\title{
Using competing models to evaluate the role of environmental pressures in ecommerce adoption by small and medium sized travel agents in a developing country
}

\author{
Mohamed A. Abou-Shouk ${ }^{\text {a }}$, Wai Mun Lim ${ }^{\text {b, * }}$, Phil Megicks ${ }^{c}$ \\ ${ }^{a}$ Faculty of Tourism and Hotels, Fayoum University, Tourism Studies Dep, PO Box 63514, Egypt \\ b School of Tourism and Hospitality, Plymouth University, Room 324, Cookworthy Building, Drakes Circus, Plymouth, PL4 8AA, UK \\ ${ }^{c}$ Plymouth Graduate School of Management, Plymouth University, Room 208, Mast House, 24 Sutton Road, Plymouth, PL4 OHJ, UK
}

\section{H I G H L I G H T S}

- Findings enrich TAM constructs by comparing competing models with the proposed extended TAM.

- The paper addresses the gaps in literature of technology adoption in developing countries.

- The measurement model developed could improve future research into SMEs' technology adoption.

- External pressures were found to positively affect the perceived benefits of adoption.

- Environmental pressures significantly influence managers' decision to adopt technology.

\section{A R T I C L E I N F O}

\section{Article history:}

Received 6 January 2015

Received in revised form 1 July 2015

Accepted 7 July 2015

Available online 25 July 2015

\section{Keywords:}

Travel agents

SMEs

E-Commerce adoption

Technology acceptance model (TAM)

Environmental pressures

Developing countries

Structural competing models

\begin{abstract}
A B S T R A C T
This study investigates the factors that influence e-commerce adoption in SME travel agents in a developing country. The research is based upon a questionnaire survey of travel agents in Egypt and employs advanced statistical techniques to test a conceptual framework that extends the technology acceptance model. Using competing models the study examines the relationship between e-commerce adoption, perceived benefits, perceived barriers and environmental pressures. The results indicate that environmental pressures significantly affect the perceived benefits and barriers of e-commerce adoption, in addition to having an indirect effect on adoption behaviour. Insights are provided into the nature of relationships between the key factors that determine e-commerce adoption and the extent to which they can be used to develop effective strategies for SME travel agent re-intermediation in the global travel market. Implications are identified for practice and government policy in relation to the use of e-commerce in SME travel businesses in developing countries.
\end{abstract}

๑) 2015 Elsevier Ltd. All rights reserved.

\section{Introduction}

Small and medium size enterprises (SMEs) are regarded as major drivers of economies and a source of employment in developing countries. As a cornerstone of entrepreneurial activity and a force for innovation, SMEs are perceived as an important facilitator of new ways of business operations development (Ongori, 2009). In order to achieve this and remain competitive in the contemporary

\footnotetext{
* Corresponding author.

E-mail addresses: maa15@fayoum.edu.eg (M.A.Abou-Shouk),wmlim@ plymouth.ac.uk (W.M. Lim), Phil.megicks@plymouth.ac.uk (P. Megicks).
}

global environment, the adoption of e-commerce is regarded as being a crucial part of their development (Ip, Leung, \& Law, 2011; Tan, Chong, Lin, \& Eze, 2009). There is no doubt that e-commerce adoption in businesses plays an important role for competitiveness and economic sustainability. E-commerce is often perceived as an empowerment tool for SMEs in terms of knowledge management, with further benefits for the creation and delivery of services in global markets (Ongori, 2009). While generally recognising the importance of e-commerce for business competitiveness, SMEs are faced with a variety of challenges when considering e-commerce implementation in their operational activities (Abdullah, Shamsuddin, Wahab, \& Hamd, 2012). 
Before businesses make decisions about whether to adopt new technology, they tend to evaluate the benefits they will gain against the costs and risks involved (Nemoto, Vasconcellos, \& Nelson, 2010). Weighing the benefits of a new technology versus its drawbacks influences businesses in their adoption decision (Hall \& Khan, 2003). In relation to new information technology, this comparison is one of the key criteria in the decision as to whether or not to adopt (Sieber \& Valor, 2008). In recent research exploring e-commerce adoption, Ongori (2009) discovered six main barriers that SMEs are facing in developing countries, namely limited funds, a lack of internal and external skills, prohibitive costs of e-commerce tools, managers being unaware of potential benefits, poor infrastructure, and the lack of a legal framework. Many SMEs in developing countries do not have the capacity to accommodate the necessary specialist knowledge for e-commerce adoption. The general technology infrastructure in developing countries is often lacking or still at the development stage, so that the technological framework supporting e-commerce is limited and cost prohibitive (Abid, Rahim, \& Scheepers, 2011; Chinn \& Fairlie, 2010; Chuang, Nakatani, \& Zhou, 2009; Khan, Moon, Rhee, \& Rho, 2010). Poor infrastructure further limits the possibilities for making optimal use of e-commerce in businesses operations (Abid et al., 2011; Ahmad, Faziharudeean, \& Zaki, 2014; James, 2011), and poorly developed data infrastructure means that there is no guarantee of a reliable internet connection, which is crucial for successful e-commerce adoption and development (Nguyen, 2009). In many developing countries, this infrastructure is still too unreliable to ensure sustainable and effective connections, imposing further barriers to successful technology adoption by SMEs (Alshawi, Missi, \& Irani, 2011). Moreover, Chuang et al. (2009) discovered that the executive decision maker's level of education is directly proportional to the extent of IT adoption in the SMEs they run which further supports a barrier to SMEs' adoption of e-commerce related to perceived knowledge, trust and skills within developing economies (Ongori, 2009).

Service-sector companies are often the most intensive users of information technology (Uwizeyemungu \& Raymond, 2011). Service sectors such as travel and tourism are generally fragmented and information-oriented industries (Andreu, Aldas, Bigne, \& Mattila, 2010). Given the intensely competitive nature of the tourism industry, travel agencies serving as intermediaries in a primarily advisory function have an urgent need to adopt e-commerce to improve their efficiency (Andreu et al., 2010). The internet is clearly a powerful tool within the travel industry, with the sector having witnessed a steady growth in its adoption as a vehicle for ecommerce in the last few decades (Buhalis \& Law, 2008). Nevertheless its adoption in travel and tourism SMEs in developing countries has only received relatively limited and fragmented coverage (Andreu et al., 2010; Tsaur, Yung, \& Lin, 2009); and although an empirical and theoretical perspective has been provided into e-commerce adoption in tourism firms more generally (El-Gohary, 2012), its investigation specifically within the context of travel agents with the ongoing challenges of their intermediary status in an increasingly uncertain environment has yet to be explored.

Moreover a variety of external pressures have been found to play a significant role in influencing SME decision-makers through the process of technology adoption. These pressures include the environment or environmental characteristics (Grandon \& Pearson, 2004; Kuan \& Chau, 2001; Lacovou, Benbasat, \& Dexter, 1995; Premkumar \& Roberts, 1999). It has often been suggested that such pressures drive SMEs to adopt technology to overcome challenges, and this is typically the case for travel agents, who face a serious threat from the disintermediation of the global travel market as a result of changes in the distribution structure that have been caused by the emergence of online intermediaries (Andreu et al., 2010; Goldmanis, Hortaçsu, Syverson, \& Emre, 2010). These pressures can also be seen as compelling travel agents to adopt technology in order to enhance their competitive positions. Effective e-commerce adoption is one of the strategies travel agents can use to re-intermediate themselves into the travel market (Álvarez, Martín, \& Casielles, 2007; Patricia, 2008).

The conceptualisation of the relationships between the benefits of and barriers to adopting technology, and the external pressures to do so are included and measured in the Technology Acceptance Model (TAM) (Davis, Bagozzi, \& Warshaw, 1989). TAM suggests that the perceived usefulness and perceived ease of use of innovation affect firms' attitudes over whether or not to adopt it. Additionally, some antecedents of perceived usefulness and perceived ease of use are expressed through external variables. By developing TAM, this research extends perceived usefulness to cover the benefits of adoption, perceived ease of use, and barriers to adoption; and also includes the environmental pressures driving SMEs to adopt technologies. The study aims to investigate the benefits, barriers, and environmental factors affecting the adoption of e-commerce by travel agents in Egypt, which places the study within the context of a developing country.

In addition to enlarging and enriching the constructs of TAM, the study compares two competing models with the proposed extended TAM. Furthermore, the present research makes a contribution to theory by addressing some gaps in the literature regarding the examination of technology adoption in developing countries (Thomas, Shaw, \& Page, 2011; Thulani, Tofara, \& Langton, 2010). It provides evidence from developing countries which can help with the rigorous generalisation of findings from developed countries to developing ones (Lawrence \& Tar, 2010; MacGregor \& Kartiwi, 2010). The study also adds to the existing body of knowledge on e-commerce adoption in the tourism sector, which is highlighted as an emergent area but one where there has been only limited research to date (Thomas et al., 2011). This is particularly the case for the travel agency sector where factors affecting technology adoption have not been thoroughly investigated hitherto (Hung, Yang, Yang, \& Chuang, 2011). The study has managerial implications, as the findings provide insights into the potential benefits, barriers and pressures surrounding the adoption of e-commerce. Being aware of these factors could improve managerial decision making, as relevant costs and benefits need to be factored into the technology adoption process. Furthermore, the study has value for policy in two respects: first it will help policy makers to highlight the benefits of technology adoption (and provides incentives for them to enhance these benefits), and it identifies the barriers to adoption and demonstrates how SMEs can be helped to overcome them; and second, the identification of factors affecting e-commerce adoption will be helpful for governmental bodies that have introduced national initiatives to encourage the uptake of technology by SMEs and the launching of operational platforms of ecommerce.

\section{Literature review}

The tourism and travel literature has used many theories and models to interpret how people behave when adopting new technology. The theory of reasoned action has often been employed to ascertain how attitudes towards a given behaviour and subjective norms affect behavioural intention (Fishbein \& Ajzen, 1975). The theory of reasoned action was extended to form the theory of planned behaviour, with the addition of a new construct of perceived behaviour control (Ajzen, 1991). These two 
theories suggest that the attitude towards a particular behaviour is based on the evaluation of the consequences of adopting the behaviour. The subjective norm is the perception of the individual's social environment and how this relates to the intended behaviour. Finally, perceived behaviour control is the perception of the ease/difficulty of adopting the intended behaviour. It can be concluded that behavioural intention is based on how individuals evaluate the consequences of a certain behaviour (positive or negative attitude), the social implications of undertaking the intended behaviour, and the perceived level of control they have of fulfilling that behaviour.

TAM was adapted from the theory of reasoned action and includes two constructs-perceived usefulness and perceived ease of use-which affect the mediating construct of intention to use technology, and in turn the actual use of technology. Perceived usefulness is also affected by perceived ease of use (Davis et al., 1989). Perceived usefulness is the belief that adopting an innovation will enhance the ability to carry out tasks, and thus processes. Ease of use denotes how much effort users believe they will have to make to use the innovation. TAM has since been simplified by the removal of the construct of attitude found in reasoned action theory, and extended by the addition of antecedents to perceived usefulness (Venkatesh \& Davis, 2000). Critics have argued that perceived usefulness and perceived ease of use may not mediate all the impacts of external variables on a system's use; and some external variables, such as the age of the user, culture or level of education, may have a direct effect on a system's use. The relationship between intention and actual use has also been highlighted as weak (Straub, Keil, \& Brenner, 1997). The gap between intention and actual use is full of uncertainties and it has been argued that actual use should be the fundamental goal and not intention (Chuttur, 2009). As it is often acknowledged that TAM is limited in its explanatory power, extended versions including antecedents to perceived ease of use have been developed (Venkatesh \& Bala, 2008).

While TAM highlights the antecedents to technology usage intentions, Rogers (1995) explains how technology proliferates with the diffusion of innovation theory. This author suggests that the adoption of new innovation progresses through various stages, beginning with the initial knowledge of an innovation, followed by persuasion to adopt, a decision over whether to adopt or reject the innovation, implementation and use of the innovation, and finally, confirmation of the decision. In the decision over whether or not to adopt, various characteristics of the innovation are considered: relative advantage (how this innovation is more advantageous to the users than competing ones), compatibility with existing values, ease of use, whether or not it can be trialled, and whether its effects on the business are observable. These characteristics reflect the concept of benefits and barriers to innovation, and how they influence people's decision to adopt. An in-depth literature review has revealed numerous variables that have been examined previously, as illustrated in Table 1. Variables concerning the perceived benefits of adoption range from improving customer satisfaction (Apulu \& Ige, 2011) and staff satisfaction (Harindranath, Dyerson, \& Barnes, 2008) or competitive advantage (Estebanez, 2010), to supporting effective re-intermediation (Alvarex et al., 2007), a benefit that is particularly relevant for the travel trade. Inevitably, while there are many benefits to adoption, there are also perceived barriers, including limited resource availability (Skoko, Ceric, \& Huang, 2008) and a lack of staff with IT/travel skills (Lawrence \& Tar, 2010).

Porter (1980) proposes that external forces affect all firms regardless of their internal decision making. These forces determine the potential profits of firms in an industry. They include the threat of potential entrants, the threat of substitute products or services, the bargaining power of suppliers, the bargaining power of buyers, and the degree of competition between existing competitors. A new construct of environmental pressures has been added into many models of adoption in the literature. These pressures have taken various forms, including external pressures (Voges \& Pulakanam, 2011), competitor pressures (Grandon \& Pearson, 2004), customer, supplier, and employee pressures (Andreu et al., 2010; Mehrtens, Cragg, \& Mills, 2001), trading partner pressures (Lacovou et al., 1995), and industry or government pressures (Andreu et al., 2010; Kuan \& Chau, 2001). Further variables within the environmental pressures construct can be found in Table 1 above. This study adopts and extends TAM in order to conceptualize the relationships between perceived benefits, perceived barriers, and environmental pressures.

According to TAM, there is a positive relationship between external variables and perceived usefulness. Recognising the positive characteristics of a system positively affects the perception of its usefulness (Davis et al., 1989; Venkatesh \& Davis, 2000). In the current model, the relationship between environmental pressures and perceived benefits is positive. Thus, greater pressure from competitors, partners, and suppliers, added to the pressure regarding the future survival of travel agents, positively affects the perception of the benefits of e-commerce adoption (H1a). Additionally, where the external characteristics of a system positively affect its ease of use (Davis et al., 1989; Venkatesh \& Davis, 2000), it is proposed that perceptions of external pressure to adopt e-commerce decrease the perceptions of barriers to adoption among travel agents, and push them to overcome these barriers (H1b).

H1a. There is a positive relationship between perceived environmental pressures and the perceived benefits of e-commerce adoption.

H1b. There is a negative relationship between perceived environmental pressures and the perceived barriers to e-commerce adoption.

TAM suggests that there is a positive relationship between the perceived usefulness of a system and the intention to use it (Davis et al., 1989; Venkatesh \& Davis, 2000). Other studies have confirmed the positive relationship between usefulness and adoption (Grandon \& Pearson, 2004; Riemenschneider, Harrison, \& Mykytyn, 2003), relative advantage and adoption (Moore \& Benbasat, 2001; Premkumar \& Roberts, 1999; Rogers, 1995; Thong, 1999), and perceived benefits and adoption (Beatty, Shim, \& Jones, 2001; Kuan \& Chau, 2001; Lacovou et al., 1995). The next hypothesis tests the relationship between the perceived benefits and actual adoption, that is, whether greater perceived benefits are more likely to lead to the adoption of e-commerce by travel agents.

H2. There is a positive relationship between the perceived benefits of adoption and actual adoption of e-commerce.

TAM confirms that, when users perceive a system as easy to use, it is more likely to be adopted (Davis et al., 1989; Grandon \& Pearson, 2004; Venkatesh \& Bala, 2008; Venkatesh \& Davis, 2000). Therefore, it is logical to assume that, if users perceive a system as difficult to use, they will be less likely to adopt it. Building on this assumption, barriers to adoption will negatively affect adoption. This hypothesis suggests that, the more travel agents perceive that there are barriers to its adoption, the less likely they will be to adopt e-commerce (H3a). Barriers to adoption can take various forms. Examples include a lack of organizational readiness (Grandon \& Pearson, 2004; Lacovou et al., 1995), incompatibility 
Table 1

Measurement scale.

\begin{tabular}{|c|c|c|}
\hline Constructs & Variables & Researchers \\
\hline \multirow[t]{15}{*}{ Benefits of adoption } & Sales, revenue and profits growth & Heung (2003); Karagozoglu and Lindell (2004) \\
\hline & Supporting effective re-intermediation & Álvarez et al. (2007) \\
\hline & Attracting new services and investment & Thulani et al. (2010) \\
\hline & Enabling and facilitating collaboration & Bourgouin (2002); Pease and Rowe (2005) \\
\hline & Customizing services to customer needs & Pease and Rowe (2005) \\
\hline & Improving customer satisfaction & Apulu and Ige (2011); Harindranath et al. (2008) \\
\hline & Increasing competitive advantages & Estebanez (2010); McAdam, Moffett, Hazlett, and Shevlin (2010) \\
\hline & Establishing reputation globally & Collins, Buhalis, and Peters (2003); Hung et al. (2011) \\
\hline & Improving distribution channels & Ayeh (2006); Saffu and Walker (2008) \\
\hline & Effective partnerships & Harindranath et al. (2008); Usoro (2007) \\
\hline & Improving accountability & Quayle (2002) \\
\hline & Enhancing staff satisfaction & Harindranath et al. (2008) \\
\hline & Ease of carrying out transactions & Álvarez et al. (2007); Raymond (2001) \\
\hline & Improving internal knowledge flow & Daniel and Wilson (2002) \\
\hline & Providing support for strategic decisions & Grandon and Pearson (2004); Saffu and Walker (2008) \\
\hline \multirow[t]{6}{*}{ Environmental pressures } & Responding to competitor pressures & Hung et al. (2011) \\
\hline & Supplier's development programmes & Quayle (2002); Vrana and Zafiropoulos (2006) \\
\hline & Business partner influence & Poon and Joseph (2001); Teo, Lin, and Lai (2009) \\
\hline & Adapting to technology changes & Law, leung, and Wong (2004) \\
\hline & Consequences of globalization & Buhalis and Deimezi (2004); Poon and Joseph (2001) \\
\hline & Future survival of travel agency & Bennett and Lai (2005); Bigne, Aldas, and Anderu (2008) \\
\hline \multirow[t]{18}{*}{ Barriers to adoption } & Limited resources available & Skoko et al. (2008) \\
\hline & Lack of skilled labour in IT/travel & Lawrence and Tar (2010) \\
\hline & Time required to replace/change & Kartiwi and MacGregor (2007); Thulani et al. (2010) \\
\hline & Employee resistance to change & Alam, Ali, and Jani (2011); Heung (2003) \\
\hline & Lack of technological readiness & Heung (2003); Warden and Tunzelana (2004) \\
\hline & Business characteristics & Beckinsale and Levy (2004); Heung (2003) \\
\hline & Business planning and strategy & Skoko et al. (2008); Zheng et al. (2004) \\
\hline & Lack of awareness of e-commerce benefits & Apulu and Ige (2011; Chen and McQueen (2008) \\
\hline & Reluctance to take risks & Alam et al. (2011); Thomas et al. (2011) \\
\hline & Lack of successful business models & Zheng et al. (2004) \\
\hline & Lack of external support & Chen and McQueen (2008); Dutta and Coury (2003) \\
\hline & Business environment & Ayeh (2006); Lawrence and Tar (2010) \\
\hline & Customer issues & Álvarez et al. (2007) \\
\hline & Legal concerns & Azam (2007); Hung et al. (2011) \\
\hline & Lack of public infrastructure readiness & Dutta and Coury (2003); Hung et al. (2011) \\
\hline & Inability to trial e-commerce & Azad and Hasan (2011); Rogers (1995) \\
\hline & E-commerce complexity & Azam (2007); Rogers (1995) \\
\hline & E-commerce not suited to services & Chen and McQueen (2008); Kartiwi and MacGregor (2007) \\
\hline
\end{tabular}

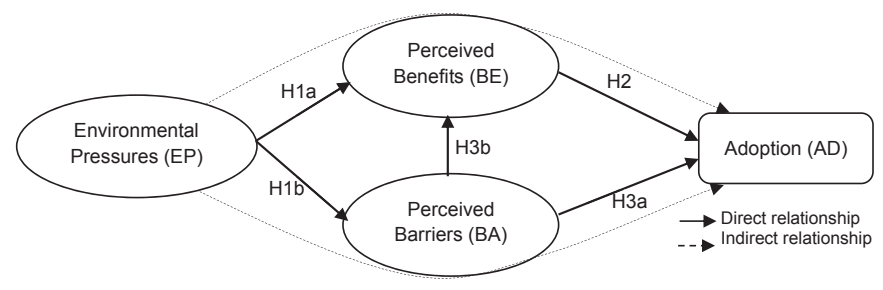

Fig. 1. The hypothetical relationships in the proposed research model.

(Azad \& Hasan, 2011; Beatty et al., 2001; Rogers, 1995), complexity (Thomas et al., 2011; Thong, 1999), lack of visibility (Moore \& Benbasat, 2001), high costs (Alam et al., 2011), security concerns (Voges \& Pulakanam, 2011; Zaied, 2012), lack of customer readiness (Scupola, 2009), lack of skilled labour (Lawrence \& Tar, 2010; Samoilenko \& Osei-Bryson, 2008), and lack of infrastructure readiness (Apulu \& Ige, 2011). Furthermore, TAM shows that perceiving a system as easy to use leads to the perception that it is useful to the business, which suggests that ease of use is a determinant of perceived usefulness (Davis et al., 1989; Riemenschneider et al., 2003). Therefore, it is assumed that, if travel agents perceive barriers to the adoption of e-commerce, this will lead to them perceiving that it has fewer benefits (H3b). Fig. 1 depicts the research hypotheses.

H3a. There is a negative relationship between the perceived barriers to adoption and actual adoption of e-commerce.
H3b. There is a negative relationship between the perceived barriers to adoption and the perception that e-commerce is beneficial to the business.

Two competing models are incorporated in this study for comparison with the main model. In the literature, many studies have relied on TAM to provide the theoretical background to the research (e.g., Ayo, Adewoye, \& Oni, 2011; Hernandez, Jimenez, \& Martın, 2009; Klloppiing \& McKiinneyy, 2004; Usoro, Shoyelu, \& Kuofie, 2010). In these studies, the researchers have excluded the relationship between perceived ease of use and perceived usefulness. Based on these studies, in the first competing model of this paper, the relationship between perceived barriers to adoption and perceived benefits of adoption is removed. Excluding this relationship means assuming that the perceived barriers to adoption are not a determinant of the perceived benefits of adoption, and that managers separately weigh the perceived benefits and barriers when deciding whether to adopt.

The second competing model is based on the definition of enabling factors in e-commerce adoption. Some researchers combine environmental pressures with the perceived benefits of adoption to form one construct, named enablers of adoption (Lacovou et al., 1995; Voges \& Pulakanam, 2011). In this competing model, there are two main constructs affecting the actual adoption of e-commerce which are enabling factors and barriers to adoption. It is proposed that enabling factors positively affect adoption, while barriers negatively affect it. 


\section{Materials and methods}

\subsection{Research context}

Support for the selection of Egypt as the setting for this study are provided by the descriptive statistics regarding travel agents with a web presence. In Egypt 34.0\% of travel agents in have websites, while $27.8 \%$ have e-mail only and $38.2 \%$ have neither websites nor e-mail. Within the group of Category A travel agents, 418 (40.8\%) have websites, while 605 agents (59.2\%) do not (Egyptian Travel Agents Association, 2008). Category A travel agents are those licensed to work globally on inbound and outbound tourism activities. Although these businesses need to improve their competitive positions, the statistics highlight the aforementioned relatively low level of adoption of e-commerce through the use of websites and e-mail facilities. To survive, travel agents depend on tour operators as one of their major suppliers. It should be noted that Egyptian travel agents cannot be classified as tour operators, which are considered to be large companies that specialize in designing and selling inclusive tours. As the majority of international tourists arriving in developing countries come from developed countries, and particularly Europe, the vast majority of the travel and tourism arrangements are organized by tour operators based in developed countries. The difference between travel agents in developed countries and those in Egypt is that the largest tour operators in developed countries have their own travel agents (e.g., Lunn Poly is owned by Thomson in the UK) (Meyer, 2003), while Egyptian travel agents work for foreign tour operators for an agreed commission.

Adding to this, it is believed that small travel agents have suffered significantly from the changes e-commerce has produced in the travel distribution structure (Goldmanis et al., 2010), namely reduced intermediation in the global travel market. Furthermore, the Egyptian government has allowed foreign tour operators to set up their own travel agents in Egypt, increasing the competition and putting Egyptian travel agents under strong threat of disintermediation. One way for travel agents to survive and re-intermediate themselves is to be technology oriented and adopt e-commerce practices, which could provide benefits to support their future survival.

\subsection{Measurement scale and data collection}

There are four constructs in the proposed research model (Fig. 1): environmental pressures, perceived benefits of adoption, perceived barriers to adoption and e-commerce adoption. The first three constructs are latent variables, with multiple items (indicators) measured using a five-point Likert scale to enhance validity. The fourth is a dichotomous variable (adoption), equal to 1 for adopters and 0 for non-adopters of e-commerce. Through a review of the literature on technology adoption, internet diffusion, ecommerce adoption and information systems (i.e., Álvarez et al., 2007; Ayeh, 2006; Beatty et al., 2001; Bourgouin, 2002; Daniel, Wilson, \& Myers, 2002; Hung et al., 2011; MacGregor \& Kartiwi, 2010; Mehrtens et al., 2001; Thong, 1999), an extensive list of environmental pressures, perceived benefits and perceived barriers was generated. The initial list was then refined, leaving the most relevant items for this study.

The survey instrument included 26 benefits, 18 environmental pressures and 22 barriers to adoption. The initial questionnaire was assessed by $15 \mathrm{PhD}$ researchers for face validity (Zikmund, 2000). The form was then revised to address clarity and design concerns. The next stage involved sending the form to five academics (three lecturers in the UK and two professors in Egypt) to check whether the measuring instrument accurately reflected what it was supposed to measure (DeVellis, 2003; Netemeyer, Bearden, \& Sharma, 2003). The academics all recommended piloting the initial form on travel agents. Therefore, it was piloted on 50 travel agents in Egypt, and the results were tested using reliability statistics, and corrected-item-total correlations for construct validity purposes (Litwin, 1995; Netemeyer et al., 2003). After this, items with corrected-item-total correlation loadings between .35 and .80 were chosen (Netemeyer et al., 2003), to leave 15 benefits, 6 environmental pressures and 18 barriers to be included in the final questionnaire (Table 1 ).

The questionnaire, originally written in the English language, was translated into Arabic, the first language of the respondents, before it was pre-tested. The mixed-method for translation validity was used (Saunders, Thornhill, \& Lewis, 2009). The English questionnaire was translated into Arabic, then the Arabic copy was translated back into English, and the new English copy was compared to the original. Based on the literature review, adopters of e-commerce can be starters (using a static website and email to communicate with customers) or advanced adopters (using an interactive website and online booking with online payment) (AlQirim, 2007; Bigne-Alcaniz, Aldas-Manzano, Andreu-Simo, \& Ruiz-Mafe, 2009), while non-adopters are those agents with neither a static nor an interactive website.

A face-to-face survey was undertaken of 826 agents based in Greater Cairo (Egyptian Travel Agents Association, 2008) chosen using a stratified sampling technique. Complete and valid questionnaires, free of missing data, were collected from 411 respondents - 202 adopters and 209 non-adopters - a response rate of $49.8 \%$.

\subsection{Data analysis}

The MPlus program (Version 6) was applied in order to analyse the data using structural equation modelling (SEM). SEM, as a confirmatory multivariate technique that includes the measurement errors in the model and allows one to measure the relationships between the latent and observed variables (Robson, 2002), was used to investigate the causal relationships between the constructs. SEM establishes both measurement and structural models to address complicated relationships (Hair, Black, Babin, \& Anderson, 2010). The sample size of 411 agents, representing 10 cases for each measured indicator, is considered large (Finney \& DiStefano, 2006). As the dependent variable was dichotomous and a Likert scale was used, the assumption of normality was violated (Hoe, 2008; Kaplan, 2000; Stevens, 1996). Robust weighted least squares estimation methods (WLSMV), and robust maximum likelihood (MLR), from MPlus, were used to address the nonnormality concerns (Enders, 2005). Chi-squared statistics $\left(\chi^{2}\right), \chi^{2}$ / df, the comparative fit index (CFI), the Tucker-Lewis index (TLI), the root mean square error of approximation (RMSEA), the standardized root mean square residual (SRMR), and the weighted root mean square residual (WRMR) were used to assess model fit.

Construct validity was assessed by looking at both discriminant and convergent validity, by comparing average variance extracted (AVE) (Fornell \& Larcker, 1981) with the squared inter-construct correlation (SIC) (Dalgaard, 2008). The competing models strategy was used, in which the estimated model is compared with competing models that provide alternative explanations of the data (Hair et al., 2010; MacCallum \& Austin, 2000). The research model was compared with the competing models based on the concept of nested models and using the Chi-squared difference (Bentler \& Satorra, 2010; Hair et al., 2010), taken from the DIFFTEST function in MPlus (Muthén \& Muthén, 1998-2010). The comparison of the two competing models was based on the concept of non-nested models using three steps: comparing the fit indices, the path 
coefficients, and the variance explained $\left(\mathrm{R}^{2}\right)$ (Lee \& Back, 2008).

Among the 411 travel agents who responded, it was found that 386 agents used computers in their daily activities, while 25 used traditional paper-based methods. Of all the agents, $34.8 \%$ indicated that they had an IT department, while $65.2 \%$ said that they did not. A total of 374 agents had internet access in their companies and 37 did not. Among the 374 with internet access, 94.7\% used the internet to collect information about competitors, $92.2 \%$ to communicate with and respond to customers, 91.4\% to collect information about customers, $89 \%$ to promote their agency, $85.3 \%$ to search for customers and/or suppliers, $73 \%$ to bid for contracts, $55.9 \%$ to receive customer bookings, $54.8 \%$ to monitor hits on websites, and $52.1 \%$ to provide formal staff training. According to the results, 202 of the agents had adopted either a low or advanced level of e-commerce, while 209 had not.

\section{Results}

\subsection{Measurement model}

Exploratory factor analysis was undertaken on the 411 cases, revealing eight factors. The benefits of adoption were categorized into three factors: essential benefits (sales and profits growth, sales, supporting effective re-intermediation, attracting new services and investment, and enabling and facilitating collaboration), marketing and competition benefits (customizing services to customer needs, improving customer satisfaction, increasing competitive advantage, establishing a reputation in the global markets, and improving distribution channels), and internal business efficiency benefits (effective partnerships, improving accountability, enhancing staff satisfaction, ease of carrying out transactions, improving internal knowledge flow and sharing, and providing support for strategic decisions).

Environmental pressures loaded on one factor (responding to competitor pressures, suppliers' development programmes, business partner influence, adapting to technology changes, globalization consequences, and future survival of the travel agency).

Barriers to adoption were classified into four factors: resource limitations (limited resources available, lack of skilled labour in IT/ travel, time required to change, and employee resistance to change), business internal environment (lack of technological readiness, business characteristics, business planning and strategy, lack of awareness of e-commerce benefits, and reluctance to take risks), business external environment (lack of successful and proven business models, lack of external support, business environment, customer issues, legal concerns, and lack of public infrastructure readiness), and attributes of the adopted technology (inability to trial e-commerce, complexity of e-commerce, and ecommerce's lack of suitability to the nature of the services provided).

Running a confirmatory factor analysis on the above eight factors provided the following results: $\chi^{2}=905.616, \mathrm{df}=674, \chi^{2}$ / $\mathrm{df}=1.35$, RAMSEA $=.029$, confidence intervals of .024 and .034 , $\mathrm{CFI}=.961, \mathrm{TLI}=.957$ and SRMR $=.043$ for the first-order model; and $\chi^{2}=930.906, \mathrm{df}=692, \chi^{2} / \mathrm{df}=1.35$, RAMSEA $=.029$, confidence intervals of .024 and .034, CFI $=.960$, TLI $=.957$ and SRMR $=.046$ for the second-order model. These results illustrated that the fit indices were within target values and that the measurement instrument was valid for measuring what it was intended to measure (Byrne, 2009; Hox, 2010; MacCallum, Browne, \& Sugawara, 1996). Examining the construct validity, the results indicated that the AVE values were greater than .5 for all constructs, confirming the existence of convergent validity (Fornell \& Larcker, 1981). Meanwhile, the AVEs were greater than the SICs for all constructs, proving the discriminant validity of the model
(Dalgaard, 2008). Cronbach's alpha and the composite reliability (CR) values were greater than .7 for all constructs, showing that the scales were reliable (Hair et al., 2010) (see Table 2).

In a measurement model, the standardized loading is the measure's correlation with the latent variable. These loadings could be explained as the regressive paths of indicators on their latent variables. They are similar to the loadings of indicators on factors in factor analysis. According to Field (2009), loadings below .35 are candidates for exclusion. Furthermore, Hoe (2008) proposed that standardized paths should be above .30 in order to be considered meaningful.

\subsection{Structural model and hypothesis tests}

The structural model (Fig. 2) shows a good fit to the data: $\chi^{2}=818.264, \mathrm{df}=729, \chi^{2} / \mathrm{df}=1.12$, RAMSEA $=.017$, confidence intervals are .009 and $.026, \mathrm{CFI}=.936, \mathrm{TLI}=.931$ and $\mathrm{WRMR}=.688$.

The test of the first hypothesis (H1a), proposing that environmental pressures (EP) positively affect the perceived benefits of adoption (BE), reveals that $\beta_{\mathrm{EP} \rightarrow \mathrm{BE}}=.557, \mathrm{p}<0.01$, confirming the positive relationship. For H1b, hypothesising a negative relationship between environmental pressures and perceived barriers to adoption (BA), the test reveals $\beta_{\mathrm{EP} \rightarrow \mathrm{BA}}=-.631, \mathrm{p}<0.01$, supporting the negative relationship. For $\mathrm{H} 2$, which proposes a positive relationship between the perceived benefits of adoption and e-commerce adoption (AD), the results of $\beta_{\mathrm{BE} \rightarrow \mathrm{AD}}=-.305, \mathrm{p}<0.01$ confirm the positive relationship. For $\mathrm{H} 3 \mathrm{a}$, which proposes a negative relationship between perceived barriers to adoption and e-commerce adoption, the test produces $\beta_{\mathrm{BA} \rightarrow \mathrm{AD}}=-.673, \mathrm{p}<0.01$, supporting the negative relationship. The results for $\mathrm{H} 3 \mathrm{~b}$, which proposes a negative relationship between perceived barriers to and perceived benefits of adoption, are $\beta_{\mathrm{BA} \rightarrow \mathrm{BE}}=-.247, \mathrm{p}<0.01$, confirming the negative relationship. To sum up, the three extended constructs in the model (EP, BE, and BA) are shown to significantly affect the adoption of e-commerce.

In terms of indirect effects, perceiving environmental pressures was found to positively affect the perceived benefits, leading to a positive indirect effect of environmental pressures on adoption via benefits $\left(\beta_{E_{-} \_B E \rightarrow A D}=.170, p<0.05\right)$. Meanwhile, perceiving environmental pressures was found to negatively affect the perceived barriers to adoption, leading to a positive indirect effect of environmental pressures on adoption via the decreasing/overcoming of barriers $\left(\beta_{\mathrm{EP} \_\mathrm{BA} \rightarrow \mathrm{AD}}=.424, \mathrm{p}<0.01\right)$. Altogether, environmental pressures were found to help maximise the perceived benefits of adoption, while decreasing and even helping firms to overcome the perceived barriers to adoption. These effects encourage and enable adoption $\left(\beta_{\mathrm{EP}}\right.$ (BE and $\left.\mathrm{BA}\right) \rightarrow$ $\mathrm{AD}=.594, \mathrm{p}<0.01)$. The probit regression of the causal relationship between the perceived benefits and perceived barriers to adoption, and the actual adoption of e-commerce, can be represented as $\mathrm{P}(\mathrm{u}=1 \mid \mathrm{x})=\mathrm{F}(-.021+.305 * \mathrm{BE}-.673 * \mathrm{BA})$ (Muthén \& Muthén, 1998-2010). Based on this equation, the probability of adoption can be calculated using the average values of the perceived benefits and barriers.

\subsection{Comparing competing models}

As presented in Table 3 below, the fit indices of the competing models are within the target values. The competing models (Fig. 3) were compared next based on the concept of nested models (Hair et al., 2010), using the chi-squared difference test The difference between the research model and the first nested model was found to be 6.945 , with 1 degree of freedom and $\mathrm{p}<0.001$. That between the research model and the second nested model was 8.964, with 1 degree of freedom and $p<0.001$. These 
Table 2

Validity and reliability of the measurement model.

\begin{tabular}{|c|c|c|c|c|c|c|c|c|c|c|c|c|c|}
\hline & \multirow[t]{2}{*}{ Items } & \multirow{2}{*}{$\begin{array}{l}\text { Standardized } \\
\text { loadings }\end{array}$} & \multirow{2}{*}{$\begin{array}{l}\text { Cronbach's } \\
\text { alpha }\end{array}$} & \multirow[t]{2}{*}{ AVE } & \multirow[t]{2}{*}{$\mathrm{CR}$} & \multicolumn{8}{|l|}{ SIC } \\
\hline & & & & & & $\mathrm{F} 1$ & $\mathrm{~F} 2$ & F3 & F4 & F5 & F6 & F7 & F8 \\
\hline \multirow[t]{4}{*}{ Essential benefits (F1) } & Sales, revenue and profit growth & .579 & .794 & .501 & .799 & - & .281 & .262 & .263 & .061 & .070 & .060 & .081 \\
\hline & Supports effective re-intermediation & .709 & & & & & & & & & & & \\
\hline & Attracts new services and investment & .775 & & & & & & & & & & & \\
\hline & Enables and facilitates collaboration & .753 & & & & & & & & & & & \\
\hline \multirow{5}{*}{$\begin{array}{l}\text { Marketing and } \\
\text { competition benefits (F2) }\end{array}$} & Customizing services to customer needs & .687 & .837 & .515 & .840 & .281 & - & .233 & .319 & .031 & .015 & .052 & .022 \\
\hline & Improved customer satisfaction & .592 & & & & & & & & & & & \\
\hline & Increased competitive advantages & .773 & & & & & & & & & & & \\
\hline & $\begin{array}{l}\text { Establishing a reputation in the } \\
\text { global markets }\end{array}$ & .769 & & & & & & & & & & & \\
\hline & Improved distribution channels & .751 & & & & & & & & & & & \\
\hline \multirow{6}{*}{$\begin{array}{l}\text { Internal business } \\
\text { efficiency (F3) }\end{array}$} & Effective partnerships & .750 & .856 & .502 & .857 & .262 & .233 & - & .161 & .019 & .021 & .023 & .078 \\
\hline & Improved accountability & .660 & & & & & & & & & & & \\
\hline & Enhanced staff satisfaction & .643 & & & & & & & & & & & \\
\hline & Ease of carrying out transactions & .755 & & & & & & & & & & & \\
\hline & $\begin{array}{l}\text { Improved internal knowledge } \\
\text { flow \& sharing }\end{array}$ & .771 & & & & & & & & & & & \\
\hline & Provides support for strategic decisions & .660 & & & & & & & & & & & \\
\hline \multirow{6}{*}{$\begin{array}{l}\text { Environmental pressures } \\
\qquad(\mathrm{F} 4)\end{array}$} & Responding to competitors' pressures & .604 & .857 & .501 & .856 & .263 & .319 & .161 & - & .067 & .040 & .101 & .120 \\
\hline & Suppliers' development programmes & .627 & & & & & & & & & & & \\
\hline & Business partners' influence & .650 & & & & & & & & & & & \\
\hline & Adapting to technology changes & .759 & & & & & & & & & & & \\
\hline & Globalization issues & .809 & & & & & & & & & & & \\
\hline & Future survival of the travel agency & .773 & & & & & & & & & & & \\
\hline \multirow[t]{4}{*}{ Resource limitations (F5) } & Limited resources available & .513 & .804 & .525 & .811 & .061 & .031 & .019 & .067 & - & .025 & .048 & .060 \\
\hline & Lack of skilled labour in IT/travel & .833 & & & & & & & & & & & \\
\hline & Time required to change & .670 & & & & & & & & & & & \\
\hline & Employee resistance to change & .834 & & & & & & & & & & & \\
\hline \multirow{5}{*}{$\begin{array}{l}\text { Internal business } \\
\text { environment (F6) }\end{array}$} & Lack of technological readiness & .698 & .832 & .529 & .841 & .070 & .015 & .021 & .040 & .025 & - & .034 & .022 \\
\hline & Business characteristics & .621 & & & & & & & & & & & \\
\hline & Business planning and strategy & .885 & & & & & & & & & & & \\
\hline & Lack of awareness of e-commerce benefits & .897 & & & & & & & & & & & \\
\hline & Reluctance to take risks & .442 & & & & & & & & & & & \\
\hline \multirow[t]{6}{*}{$\begin{array}{l}\text { External business } \\
\text { environment (F7) }\end{array}$} & $\begin{array}{l}\text { Lack of successful \& proven } \\
\text { business models }\end{array}$ & .552 & .856 & .502 & .856 & .060 & .052 & .023 & .101 & .048 & .034 & - & .080 \\
\hline & Lack of external support & .623 & & & & & & & & & & & \\
\hline & Business environment & .661 & & & & & & & & & & & \\
\hline & Customer issues & .755 & & & & & & & & & & & \\
\hline & Legal concerns & .807 & & & & & & & & & & & \\
\hline & $\begin{array}{l}\text { Lack of readiness of public } \\
\text { infrastructure }\end{array}$ & .812 & & & & & & & & & & & \\
\hline \multirow{3}{*}{$\begin{array}{l}\text { Adopted technology } \\
\text { attributes (F8) }\end{array}$} & Inability to trial e-commerce & .666 & .754 & .506 & .754 & .081 & .022 & .078 & .120 & .060 & .022 & .080 & - \\
\hline & E-commerce complexity & .764 & & & & & & & & & & & \\
\hline & E-commerce not suitable for services & .701 & & & & & & & & & & & \\
\hline
\end{tabular}

results confirm that the research model is a better fit to the data than either of the two nested models (Schermelleh-Engel, Moosbrugger, \& Müller, 2003).

Next, the two competing models were compared based on the concept of non-nested models. The first model had many free parameters compared to the more restricted second model. Also, the first competing model accounted for more variance in explaining the adoption of e-commerce (AD), with an adjusted $\mathrm{R}^{2}$ of .767 versus .730 for the second competing model. Therefore, the first competing model was found to better fit the data than the second competing model (Lee \& Back, 2008). However, the research model was found to be superior to both for investigating the relationship

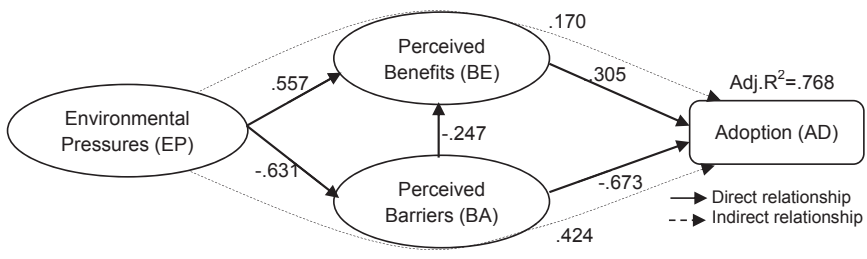

Fig. 2. The hypothesised structural model of e-commerce adoption. between the perceived barriers to adoption and the perceived benefits of adoption.

\section{Conclusions}

\subsection{Discussion of findings}

The research model used in this study indicates that the time between managers' response to environmental pressures and the making of the e-commerce adoption decision is full of uncertainties. In responding to environmental pressures, and before making their adoption decision, managers consider and evaluate both the potential benefits they can gain from adoption, and the potential barriers they might have to address in order to implement e-commerce in their enterprises. The research model provides a different perspective on how managers make their adoption decision and provides an answer to the question of why, even though managers understand the environmental pressures and believe the benefits they could gain, are still cautious about adopting e-commerce in their SME travel agents. This is simply because they encounter barriers to adoption. Looking at the statistical results, it can be seen that making the adoption decision is affected positively 
Table 3

Comparison of the competing models.

\begin{tabular}{lll}
\hline Indices & First competing model & Second competing model \\
\hline \multicolumn{2}{l}{ Fit indices (recommended value) } & \\
Chi-square $\left(\chi^{2}\right)$ & 825.292 & 841.34 \\
$\chi^{2} 2 /$ df $(<2)$ & 1.13 & 1.15 \\
RMSEA $(<.05)$ & .018 & .019 \\
CFI $(>.90$, close to .95) & .931 & .920 \\
TLI $(>.90$, close to .95) & .926 & .914 \\
WRMR $(<.9)$ & .697 & .711 \\
Path coefficients (EST/S.E.) & \\
DR-BE & $.800(17.10)$ & - \\
DR-BA & $-.715(-11.48)$ & - \\
BE-AD & $.316(3.22)$ & - \\
BA-AD & $-.670(-6.65)$ & $-.493(-4.14)$ \\
EN-AD & - & $.457(4.38)$ \\
DR-BE-AD & $.253(3.15)$ & - \\
DR-BA-AD & $.479(4.75)$ & - \\
DR-AD: total effects & $.732(16.63)$ & - \\
Explanatory power (adjusted $\left.\mathrm{R}^{2}\right)$ & \\
AD & $.790(.767)$ & $.756(.730)$ \\
BE & $.641(.603)$ & - \\
BA & $.511(.459)$ & - \\
\hline
\end{tabular}

by $32 \%$ by the benefits of adoption, and negatively by $76 \%$ by the barriers to adoption, while environmental pressures indirectly affect the adoption decision (positively $59 \%$ ) by inspiring managers to perceive the positive impacts of adoption (potential benefits) and overcome the negative factors (potential barriers to adoption).

Although the research model provides a different perspective on how managers make the adoption decision by hypothesising causal relationships among the factors affecting e-commerce adoption (i.e., pressures, benefits, and barriers). The revealed environmental pressures are in line with previous studies (i.e., Ifinedo, 2011; Kuan \& Chau, 2001). One environmental pressure identified here is the movement towards globalisation, which has encouraged SMEs to adopt technology so as to penetrate new markets and provide faster and better customer service. This finding is consistent with Kraemer et al.'s (2002) cross-country survey, which revealed that globalization drives firms to adopt e-commerce, particularly when they work globally, which is the case for travel agents. Future survival is another pressure pushing travel agents to adopt e-commerce so as to increase their sales, and improve their distribution channels and competitive positions. This is supported by the findings of a study undertaken in Taiwan (Law et al., 2004), which proposes that travel agents should be technology-oriented in order to address the threat of disintermediation.

A further environmental pressure is the need to adapt to technology changes. Travel agents need to upgrade their technologies in order to achieve improved operations. This is linked to the fourth and fifth pressures revealed in this study, namely, influence from business partners and developments made by suppliers, which push travel agents to improve the quality of their services and keep to a certain standard of service delivery. This concurs with Scupola's
(2003) study of SMEs in the south of Italy, and with Raymond's (2001) study of travel agents in Canada. The last environmental pressure identified in this research is responding to competitors. This is exacerbated by the emergence of new virtual intermediaries that put further pressure on travel agents to adopt technology. This is in line with Chwelos et al.'s (2001) study, which found that responding to competitors is a more important driver of the adoption of Electronic Data Interchange (EDI) than its perceived benefits.

As for the benefits of e-commerce adoption, it is revealed that benefits are influential factors in the adoption decision, which is similar to Acilar and Karamaşa (2011), who found that the perceived benefits are the main reason for e-commerce adoption in SME hotels in Turkey. The results of this paper revealed three categories of perceived benefits: essential, marketing and competition, and internal business efficiency. The essential benefits mostly relate to the strategic, future-oriented perspective of travel agents. This includes opportunities for growth, investment, collaboration and re-intermediation. This finding is consistent with Grandon and Pearson (2004), who point out the strategic value of e-commerce adoption.

The second category of benefits, marketing and competition, relates to improvements in the travel agents' distribution channels and the establishment of a reputation in global markets. In this respect, e-commerce is considered to be an electronic interface between the travel agents and the world, and is equivalent to opening a new sales channel, generating sales and establishing an international market presence, which is consistent with Heung's (2003) study of travel agents in Hong Kong. Furthermore, e-commerce adoption can help travel agents to customise their services to meet their customers' needs and improve customer satisfaction. Additionally, by reducing the cost of marketing, and helping travel agents to reach customers globally and to join forces with suppliers and partners, e-commerce enables them to compete with larger counterparts. This is in alignment with a previous study by Álvarez et al. (2007) on retail travel agents in Spain. The significance of the present results suggests that there is a definite focus by managers on the perceived marketing and competitive benefits of e-commerce when deciding whether to adopt.

Internal business efficiency was the third category of benefits. These benefits relate to the infrastructure that supports transactions management, the building of effective partnerships with suppliers and others, better accountability, and increased staff satisfaction. Operational efficiency enhances the ability of the SME travel agents to achieve future strategic success. This finding concurs with previous research by Harindranath et al. (2008), who found that adopting e-commerce helps SMEs to achieve internal operational efficiency, which includes providing a high-quality booking service.

On the other hand, the findings reveal that barriers to e-commerce adoption are negatively and significantly affecting the adoption decision. Firms in developing countries encounter many barriers to e-commerce adoption as a result of common

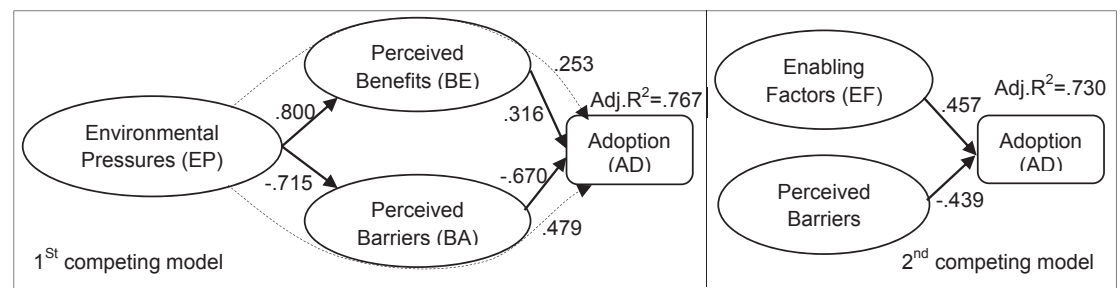

Fig. 3. The competing models. 
characteristics of these countries, such as poor infrastructure. This study has revealed four categories of barriers to adoption: attributes of the adopted technology, external business environment, internal business environment, and resource limitations. The first category includes the non-relevance of e-commerce to the nature of tourism services provided in Egypt. Most travel agents in Egypt have to fulfil a certain quota regarding religious tourism and the assumption is that e-commerce is not suitable for this type of customer, who will typically seek personal contact and advice. This viewpoint also appears in previous research by Kartiwi and MacGregor (2007) in their study of barriers to e-commerce adoption by SMEs. Also within this category is the inability to trial ecommerce to adoption highlighted in this research which refers to there being no opportunity for employees to test and assess ecommerce systems before the decision to adopt is made. The complexity of e-commerce is another perceived barrier within the category of attributes of e-commerce. This is in line with prior research based in Bangladesh claiming that employees find ecommerce difficult to use and which often requires specific training (Azam, 2007). Kendall, Tung, Chua, Ng, and Tan (2001), studying ecommerce adoption in Singaporean SMEs, agree, revealing that a lack of trialability is a significant barrier to adoption among SMEs.

The second category of barriers relates to the external business environment. This encompasses the fact that the required infrastructure is often not available in developing countries. In a recent study by Zaied (2012), inadequate infrastructure was reported to be a barrier to e-commerce adoption in Egyptian SMEs. This could include a lack of stable electricity supply, outdated telephone systems, and limited access to internet services. Another barrier in this category revealed by this study is the lack of legislation protecting e-commerce activities. This concurs with Hung et al. (2011), who found that a lack of legal regulations was a barrier to e-commerce adoption among travel agents in Taiwan. The third barrier is that customers do not trust e-commerce transactions, considering them insecure. This is very common, especially among local customers in Egypt. This matches the findings of a previous study by Chen and McQueen (2008), who claimed that the lack of trust in internet transactions affected the stages of e-commerce growth. Further barriers in this category include a lack of external support from public bodies to encourage SMEs to be technology oriented. The managers of the travel agents described a lack of governmental support, especially relating to infrastructure and e-commerce legislation. This is consistent with a previous study by Lawrence and Tar (2010), who highlighted the lack of governmental policy and support as a negative factor affecting e-commerce adoption in developing countries. The lack of successful role models adopting e-commerce is another barrier, as there is no encouragement for SMEs to adopt so as to achieve adoption benefits. This is consistent with a previous study by Zheng et al. (2004), claiming that the lack of role models discourages e-commerce among small businesses. The last barrier in this category is the business environment itself. This could include market regulations, government policies, or customers' refusal to adopt e-commerce. This is consistent with Dutta and Coury (2003), who claimed that the political systems and regulatory environments in Arab countries are dependent on foreign technologies.

The third category of barriers is resource limitations. This encompasses employees' resistance to moving away from traditional ways of working. This supports a previous study by Scupola (2009) that found employees' attitudes towards e-commerce to constrain adoption. Linked to this is the lack of IT/travel-related skilled labour. Travel agent employees have been found to lack both IT and travel knowledge, as confirmed by Heung (2003). A further barrier in this category is the time required to change from traditional to automated methods of doing work. Managers perceive that the process will take a long time and may include changing the whole system from paper-based to electronic and training employees to use the new system. Thulani et al. (2010) similarly revealed finding that SMEs in Zimbabwe lack the time to implement e-commerce. The final barrier in this category is the limited resources of the SMEs versus the high cost of e-commerce adoption. The cost includes website design, updating or upgrading technologies, maintaining the website, bank transaction fees, and the cost of marketing the website and performing search engine optimization. This finding is in line with Heung (2003), who stated that the cost of e-commerce implementation is a significant barrier to its adoption by travel agents.

The last category of barriers is the internal business environment barriers. This includes a lack of awareness of the benefits of ecommerce adoption for SMEs. This lack of awareness could be related to the managers'/owners' level of education and knowledge of computers, or a lack of more specific technical knowledge. This finding is in line with previous research by Chen and McQueen (2008). A lack of technological readiness among SMEs, mostly in relation to compatibility issues with software and hardware, is another barrier. This finding is supported by Azad and Hasan (2011), who investigated SMEs in Bangladesh. A further barrier is a lack of business planning and strategy needed to expand and adopt e-commerce. This is consistent with Kamel and Hussein (2002), who found that Egyptian companies fail to carry out strategic IT planning. Furthermore, some business characteristics, such as the small size of the travel agents surveyed and their remote geographical locations also act as potential barriers. The final barrier in this category is the reluctance of the SMEs to take risks, often caused by uncertainty over the benefits they may receive from ecommerce. This finding is in line with a previous study by Olatokun and Kebonye (2010), who found that SMEs in Bostwana perceive ecommerce implementation to involve high risks.

Using the competing models approach in this study provided different perspectives of how managers make the adoption decision, first by combining the environmental pressures and benefits of adoption into 'enabling factors', and second by restricting the effect of barriers to adoption on the perceived benefits. However, the competing models do not provide the full picture of how managers make their decisions; compared to the research model proposed in this paper, they provide a weak explanation of the variance in the adoption decision. Using such a strategy provided more than one interpretation of the data and allowed us to test different perspectives on how the adoption decision is made.

By way of summary, travel agents are one of the sectors of the travel industry that has suffered the most from the emergence of online intermediaries and changes in the market distribution structure caused by e-commerce (Goldmanis et al., 2010). As travel service providers, adopting e-commerce and maximizing the benefits of adoption could support travel agents' survival (Álvarez et al., 2007; Patricia, 2008). At a time when foreign tour operators are being allowed to open their own travel agents in Egypt, increasing the competition and leading to the disintermediation of Egyptian travel agents from the global market, understanding the factors that influence the adoption of e-commerce could help travel agents to benefit from this technology and enhance their competitive positions.

This paper investigates the influence of perceived environmental pressures on the perceived benefits of and perceived barriers to adoption, which in turn affect e-commerce adoption. It explores the interaction between the three constructs and their effects on the e-commerce adoption decision. The research findings reveal that external pressures positively affect the perceived benefits of adoption and help to decrease and even overcome barriers to adoption. Meanwhile, the perceived benefits are negatively 
affected by the perceived barriers to adoption, and the perceived benefits positively affect the adoption of e-commerce, while barriers to adoption have a negative impact on adoption.

Awareness and understanding of the factors that explain why a particular innovation is accepted or not are useful for practitioners, who can then take the required corrective action. This study uses competing models that provide different perspectives of the adoption factors, comparative interpretations of how the factors affect the adoption of e-commerce, and varying explanations of the interactions among adoption factors.

In terms of environmental pressures, agents perceive the consequences of globalization as a major pressure to adopt technology, followed in importance by the need to ensure the future survival of the travel agency. In terms of the perceived benefits of e-commerce adoption, it is found that agents perceive attracting new services and investment as the most essential benefits of e-commerce adoption. Establishing a reputation in the global market is perceived to be the greatest marketing benefit of adoption. Ease of carrying out transactions is perceived to be the greatest internal efficiency benefit of adoption. In terms of barriers, travel agents perceive e-commerce's unsuitability for some of their services and a lack of readiness of public infrastructure as two external environmental barriers to adoption. They perceive employee resistance to changing from traditional ways of working to be a resource limitation. Finally, they perceive a lack of awareness of the ecommerce benefits for SMEs as an internal environmental barrier to adoption.

\subsection{Theoretical implications}

The contributions of this study to theory are twofold; it offers an overall understanding of the factors affecting e-commerce adoption in SMEs together with a methodological contribution. From the literature review, it is clear that travel agents face the threat of disintermediation of the global travel market as a result of changes in the distribution structure caused by e-commerce and competition from foreign tour operators that are now allowed to set up their own travel agents in Egypt. Instead of adopting e-commerce and gaining from its potential, SME travel agents are characterised by their slow adoption of technology in general and e-commerce in particular. More research is needed to identify the factors that affect the adoption of e-commerce, as these factors have not been well documented in the context of the travel sector so far, and especially in developing countries (Abou-Shouk, Lim, and Megicks, 2013; Hung et al., 2011; Thomas et al., 2011; Thulani et al., 2010). The generalisation to developing countries of the factors that apply to developed countries lacks rigour (Lawrence \& Tar, 2010; MacGregor \& Kartiwi, 2010).

This study aimed to identify the factors that affect e-commerce adoption in the travel agency sector. The findings help to provide a better understanding of e-commerce adoption behaviour in tourism enterprises, especially in developing countries, where few studies have been conducted on technology adoption to date. Although recent studies have looked at e-commerce adoption in developing countries (i.e. Ayo et al., 2011; Azad \& Hasan, 2011; Hung et al., 2011; MacGregor \& Kartiwi, 2010), they have only studied the barriers. This study, therefore, provides further understanding of the inter-relationships among all the factors that affect the adoption of e-commerce.

The findings help to answer the question of why SMEs are reluctant to adopt technology even though it could improve their competitive position and survival chances. Although environmental pressures push travel agents to adopt e-commerce, some agents do not believe that benefits can be gained from adoption, while others believe there are benefits and have taken some steps towards adoption but face barriers that prevent them from benefitting fully. Additionally, this study reflects the perceptions of e-commerce in Egypt in particular, thus offering the perspective of a developing country, and could be used in the future to make comparisons so as to analyse the progress of e-commerce adoption by SME travel agents.

Furthermore, the measurement model developed in this study and the procedures used to ensure validity and reliability could be useful for academics and researchers conducting further research into SMEs' technology adoption. This study also contributes to the theory by modifying TAM. Extending the 'usefulness' construct in TAM to include the benefits of adoption, replacing 'ease-of-use' with barriers to adoption and 'external variables' with environmental pressures, supports TAM's ability to explain the factors affecting the adoption of complex innovations. The modified TAM highlights the importance of benefits, barriers and environmental pressures as key determinants of e-commerce adoption. It explores the mediating effects of benefits and barriers. The study's findings reveal that the modified TAM has good explanatory power in interpreting e-commerce adoption.

The measurement model revealed in this study could also be used to investigate other disciplines of technology adoption and different categories of small tourism enterprises. Another methodological contribution is the use of the competing models strategy to compare the research model with two other models and prove its applicability to the data. Using this strategy also helps to provide different interpretations of the data, and therefore gives varying perspectives on which theory interprets the data better. The study also highlights the use of a statistical strategy to compare competing models based on the concept of nested and non-nested models.

\subsection{Managerial implications}

There are implications for both the managers of travel agencies and policy makers. Recognising the factors affecting e-commerce adoption could enable managers to devise strategies to expand their business and gain the perceived benefits of adoption, while at the same time identifying any defects or training needs that represent barriers. Based on the results of this study, managers will be able to prepare better agendas for expansion and set priorities regarding the implementation of e-commerce. The findings of this study reveal that essential benefits are perceived to be the greatest factor affecting adoption. This could form the initial aim in the basic adoption of e-commerce. Later development strategies could include a route map for upgrading the adoption level and achieving more strategic benefits.

The findings reveal that future survival is supported by the adoption of e-commerce, and this should provide an incentive to travel agency managers to become more technology-oriented so as to improve their competitive position. Attracting new services and investment could help travel agents to work independently from tour wholesalers, airlines and hotels; this could be achieved by adopting e-commerce. Collaboration with other travel partners could strengthen their competitive advantage, support their sales and revenues, and increase their opportunities to expand, penetrate new international markets and increase their customer base.

It has been revealed in this study that the adoption of e-commerce can help travel agents to establish a reputation in global markets, which in turn increases customer satisfaction and loyalty. Hence managers, as the decision makers regarding adoption by SME travel agents, should be encouraged to invest in technology. Additionally, the adoption of e-commerce improves staff satisfaction, encouraging them to do a better job in serving 
customers, and enhancing their commitment to the company. Managers might also note that adopting e-commerce can improve internal business efficiency by increasing internal knowledge sharing and accountability among employees, and enhancing the process of strategic managerial decision making.

On the other hand, a lack of resources is not perceived to be the major barrier to adoption; technology attributes (complexity, lack of trialability and lack of suitability of e-commerce) are thought to have the greatest effect on the travel agents' decision. Therefore, e-commerce solution providers are also partly responsible for the delayed adoption of technology by SMEs. They need to facilitate the process by customizing their solutions to meet the needs of SMEs wanting to adopt e-commerce. Furthermore, recognising the factors that affect e-commerce adoption could encourage government bodies and policy makers to take action, such as introducing protective and financial legislation to encourage SMEs to adopt, or formulating national policies aimed specifically at supporting the adoption of e-commerce by SMEs. Governments could also introduce national initiatives to encourage the adoption of technology by SMEs, from two aspects. Firstly, they could promote an awareness of e-commerce and its benefits for SMEs. Secondly, they could decrease the barriers to adoption, by improving public infrastructure services and the technical support that is available for SMEs.

\subsection{Limitations and directions for future research}

The present research has a number of limitations. First, it investigates the perceptions of travel agents regarding e-commerce adoption and not the actual realised benefits or the actual barriers hindering adoption. The study is restricted to Category A travel agents, excluding Categories B and C. Category A travel agents were selected because they are licensed to work locally and globally, and their capital and activities could allow them to adopt e-commerce and enhance their competitive position and operational efficiency.

There were sampling limitations, because selecting Greater Cairo as the geographical sampling frame restricted the data collected to a large part of Egypt but not all of it. Using the last available edition of the travel agents directory, issued in 2008, may have led to some out-of-date statistics regarding travel agents in Egypt. Building upon the discussed limitations, there are several directions that further research could take. These include the identified benefits of and barriers to adoption, with a stronger focus on the adoption level so as to distinguish how the benefits and barriers relate to each level. Comparing the perceived against the actual benefits and barriers could be another interesting area for future research. Furthermore, future research could investigate how e-commerce solution providers support e-commerce adoption, as a new explanatory variable. The e-marketing challenges related to e-commerce websites represent another explanatory variable that should be included in future studies so as to measure its effect on the adoption of e-commerce. Next, a comparative study of two developing countries could contribute to the knowledge of, and provide new insights into, the factors that affect e-commerce adoption in developing countries. This could add to the applicability and generalisability of the model developed in this study.

\section{References}

Abdullah, N. H., Shamsuddin, A., Wahab, E., \& Hamd, A. (December 3-4 2012). Preliminary qualitative findings on technology adoption of Malaysian SMEs. IEEE Colloquium on Humanities Science \& Engineering Research, 15-20.

Abid, A. A., Rahim, A. M., \& Scheepers, H. (2011). Experienced benefits and barriers of e-business technology adoption by SME suppliers. Communications of the
BIMA, 11. http://dx.doi.org/10.5171/2011.7917780. Article ID 791778.

Abou-Shouk, M., Lim, W. M., \& Megicks, P. (2013). Internet adoption by travel agents a case study of Egypt. International Journal of Tourism Research, 15, 298-312.

Acilar, A., \& Karamaşa, Ç. (2011). Factors affecting the adoption of e-commerce by small businesses: a case study of a small hotel. International Journal of Information Communication Technologies and Human Development, 3(3), 31-41.

Ahmad, S. Z., Faziharudeean, T. M., \& Zaki, K. A. M. (2014). An empirical study of factors affecting e-commerce adoption among small and medium sized enterprises in a developing country: Evidence from Malaysia, information technology for development. http://dx.doi.org/10.1080/02681102.2014.

Ajzen, I. (1991). The theory of planned behaviour. Organizational Behaviour and Human Decision Processes, 50, 179-211.

Al-Qirim, N. (2007). A research trilogy into e-commerce adoption in small businesses in New Zealand. Electronic Markets, 17, 263-285.

Alam, S., Ali, M., \& Jani, M. (2011). An empirical study of factors affecting electronic commerce adoption among SMEs in Malaysia. Journal of Business Economics and Management, 12, 375-399.

Alshawi, S., Missi, F., \& Irani, Z. (2011). Organisational, technical and data quality factors in CRM adoption - SMEs perspective. Industrial Marketing Management, 40(3), 376-383.

Álvarez, L., Martín, A., \& Casielles, R. (2007). Relationship marketing and information and communication technologies: analysis of retail travel agencies. Journal of Travel Research, 45, 453-463.

Andreu, L., Aldas, J., Bigne, J., \& Mattila, A. (2010). An analysis of e-business adoption and its impact on relational quality in travel agency-supplier relationships. Tourism Management, 31, 777-787.

Apulu, I., \& Ige, E. (2011). Are Nigeria SMEs effectively utilizing e-commerce? International Journal of Business and Management, 6, 207-214.

Ayeh, J. (2006). Determinants of internet usage in Ghanaian hotels: the case of the Greater Accra Region (GAR). Journal of Hospitality \& Leisure Marketing, 15, 87-109.

Ayo, C., Adewoye, J., \& Oni, A. (2011). Business-to-consumer e-commerce in Nigeria: prospects and challenges. African Journal of Business Management, 5, 5109-5117.

Azad, M., \& Hasan, M. (2011). E-commerce aspect of developing countries like Bangladesh. International Journal of Research and Reviews in Computer Engineering, 1, 55-60.

Azam, M. (2007). Internet adoption and usage in Bangladesh. Japanese Journal of Administrative Science, 20, 43-54.

Beatty, R., Shim, J., \& Jones, M. (2001). Factors influencing corporate web site adoption: a time-based assessment. Information \& Management, 38, 337-354.

Beckinsale, M., \& Levy, M. (2004). SMEs and internet adoption strategy: who do SMEs listen to?. In Paper presented at 13th European conference on information systems, 14-16 June, Turku, Finland.

Bennett, M., \& Lai, C. (2005). The impact of the internet on travel agencies in Taiwan. Journal of Tourism and Hospitality Research, 6, 1-17.

Bentler, P., \& Satorra, A. (2010). Testing model nesting and equivalence. Psychological Methods, 15, 111-123.

Bigne-Alcaniz, E., Aldas-Manzano, J., Andreu-Simo, L., \& Ruiz-Mafe, C. (2009). Business-to-Business e-commerce adoption and perceived benefits: evidence from small and medium Spanish enterprises. International Journal of Electronic Business, 7, 599-624.

Bigne, J., Aldas, J., \& Anderu, L. (2008). B2B services: IT adoption in travel agency supply chains. Journal of Services Marketing, 22, 454-464.

Bourgouin, F. (2002). Information communication technologies and the potential for rural tourism SMME development: the case of the Wild Coast. Development Southern Africa, 19, 191-212.

Buhalis, D., \& Deimezi, O. (2004). E-tourism developments in Greece: information communication technologies adoption for strategic management of the Greek tourism industry. Tourism and Hospitality Research, 5, 103-130.

Buhalis, D., \& Law, R. (2008). Progress in information technology and tourism management: 20 years on and 10 years after the internet - the state of etourism research. Tourism Management, 29(4), 609-623.

Byrne, B. (2009). Structural equation modeling with AMOS: Basic concepts, applications, and programming (2nd ed.). New York: Routledge/Taylor \& Francis.

Chen, J., \& McQueen, R. (2008). Factors affecting e-commerce stages of growth in small Chinese firms in New Zealand: an analysis of adoption motivators and inhibitors. Journal of Global Information Management, 16, 26-60.

Chinn, M. D., \& Fairlie, R. W. (2010). ICT use in the developing world: an analysis of differences in computer and internet penetration. Review of International Economics, 18(1), 153-167.

Chuang, T. T., Nakatani, K., \& Zhou, D. (2009). An exploratory study if the extent of information technology adoption in SMEs: an application of upper echelon theory. Journal of Enterprise Information Management, 22(1), 183-196.

Chuttur, M. Y. (2009). Overview of the technology acceptance model: origins, developments and future directions, Indiana University, USA. Sprouts, 9(37). Working Papers on Information Systems.

Chwelos, P., Benbasat, I., \& Dexter, A. (2001). Research report: empirical test of an EDI adoption model. Information Systems Research, 12, 304-321.

Collins, C., Buhalis, D., \& Peters, M. (2003). Enhancing SMTEs business performance through the internet and e-learning platforms. Education + Training, 45, $483-494$.

Dalgaard, P. (2008). Introductory statistics with $R$, statistics and computing series (2nd ed.). Springer.

Daniel, E., \& Wilson, H. (2002). Adoption intensions and benefits realised: a study of 
e-commerce in UK SMEs. Journal of Small Business and Enterprise Development, 9, 331-348.

Daniel, E., Wilson, H., \& Myers, A. (2002). Adoption of e-commerce by SMEs in the UK: towards a stage model. International Small Business Journal, 20, 253-270.

Davis, F., Bagozzi, R., \& Warshaw, P. (1989). User acceptance of computer technology: a comparison of two theoretical models. Management Science, 35, 982-1003.

DeVellis, R. (2003). Scale development: Theory and applications (2nd ed., Vol. 26). London: Sage Publications.

Dutta, S., \& Coury, M. E. (2003). Chapter 8: E-COMMERCE challenges for the Arab World. In S. Dutta, B. Lanvin, \& F. Paua (Eds.), The global information technology report: Readiness for the networked world (pp. 116-131). New York, Oxford: World Economic Forum.

Egyptian Travel Agents Association. (2008). Agencies directory. Cairo, Egypt: ETAA, Ministry of Tourism.

El-Gohary, H. (2012). Factors affecting E-Marketing adoption and implementation in tourism firms: an empirical investigation of Egyptian small tourism organisations. Tourism Management, 33, 1256-1269.

Enders, C. (2005). An SAS macro for implementing the modified Bollen-Stine bootstrap for missing data: implementing the bootstrap using existing structural equation modeling software. Structural Equation Modeling: A Multidisciplinary Journal, 12, 620-641.

Estebanez, R. (2010). Information technology implementation: evidence in Spanish SMEs. International Journal of Accounting and Information Management, 18, 39-57.

Finney, S., \& DiStefano, C. (2006). Non-normal and categorical data in structural equation modeling. In G. Hancock, \& R. Mueller (Eds.), Structural equation modeling: A second course (pp. 269-314). USA: Informatio Age Publishing.

Fishbein, M., \& Ajzen, I. (1975). Belief, attitude, intention, and behaviour: An introduction to theory and research. Don Mills, Ontario: Addison-Wesley Publication.

Fornell, C., \& Larcker, D. (1981). Evaluating structural equation models with unobservable variables and measurement error. Journal of Marketing Research, 18, 39-50.

Goldmanis, M., Hortaçsu, A., Syverson, C., \& Emre, Ö. (2010). E-commerce and the market structure of retail industries. The Economic Journal, 120, 651-682.

Grandon, E., \& Pearson, J. (2004). Electronic commerce adoption: an empirical study of small and medium US businesses. Information \& Management, 42, 197-216.

Hair, J., Black, W., Babin, B., \& Anderson, R. (2010). Multivariate data analysis: A global perspective (7th ed.). Pearson Prentice Hall.

Hall, B., \& Khan, B. (2003). Adoption of new technology. In D. Jones (Ed.), New economy handbook (pp. 230-251). Amsterdam: Elsevier Science.

Harindranath, G., Dyerson, R., \& Barnes, D. (2008). E-COMMERCE adoption and use in UK SMEs: a failure of initiatives? The Electronic Journal of Information Systems Evaluation, 11, 91-96.

Hernandez, B., Jimenez, J., \& Martın, J. (2009). Adoption vs acceptance of e-commerce: two different decisions. European Journal of Marketing, 43, 1232-1245.

Heung, V. (2003). Barriers to implementing e-commerce in the travel industry: a practical perspective. International Journal of Hospitality Management, 22, $111-118$.

Hoe, S. (2008). Issues and procedures in adopting structural equation modeling technique. Journal of Applied Quantitative Methods, 3, 76-83.

Hox, J. (2010). Multilevel analysis: Techniques and applications (2nd ed.). London: Routledge.

Hung, Y., Yang, Y., Yang, H., \& Chuang, Y. (2011). Factors affecting the adoption of ecommerce for the tourism industry in Taiwan. Asia Pacific Journal of Tourism Research, 16, 105-119.

Ifinedo, P. (2011). Internet/e-business technologies acceptance in Canada's SMEs: an exploratory investigation. Internet Research, 21, 255-281.

Ip, C., Leung, R., \& Law, R. (2011). Progress and development if information and communication technologies in hospitality. International Journal of Contemporary Hospitality Management, 23(4), 533-551.

James, J. (2011). Internet skills in developing countries: how much do we know? Information Development, 27(2), 94-99.

Kamel, S., \& Hussein, M. (2002). The emergence of e-commerce in a developing nation, case of Egypt. Benchmarking: an International Journal, 9, 146-153.

Kaplan, D. (2000). Structural equation modeling: Foundations and extensions. London: Thousand Oaks, CA: Sage Publications.

Karagozoglu, N., \& Lindell, M. (2004). Electronic commerce strategy, operations, and performance in small and medium sized enterprises. Journal of Small Business and Enterprise Development, 11, 290-301.

Kartiwi, M., \& MacGregor, R. (2007). Electronic commerce adoption barriers in small to medium-sized enterprises (SMEs) in developed and developing countries: a cross country comparison. Journal of Electronic Commerce in Organization, 5, $35-51$.

Kendall, J., Tung, L., Chua, K., Ng, D., \& Tan, S. (2001). Receptivity of Singapore's SMEs to electronic commerce adoption. Journal of Strategic Information Systems, 10 223-242.

Khan, F., Moon, J., Rhee, C., \& Rho, J. J. (2010). E-government skills identification and development: toward a staged-based user-centric approach for developing countries. Asia Pacific Journal of Information Systems, 20(1), 1-31.

Klloppiing, I., \& McKiinneyy, E. (2004). Extending the technology acceptance model and the task-technology fit model to consumer e-commerce. Information Technology, Learning, and Performance Journal, 22(1), 35-48.

Kraemer, K., Gibbs, J., \& Dedrick, J. (2002). Impacts of globalization on e-commerce adoption and firm performance: A cross-country investigation. Irvine: Center for
Research on Information Technology and Organizations, University of California.

Kuan, K., \& Chau, P. (2001). A perception-based model for EDI adoption in small businesses using technology-organization-environment framework. Information \& Management, 38, 507-521.

Lacovou, C., Benbasat, I., \& Dexter, A. (1995). Electronic data interchange and small organizations: adoption and impact of technology. MIS Quarterly, 19, 465-485.

Law, R., leung, K., \& Wong, J. (2004). The impact of the internet on travel agencies. International Journal of Contemporary Hospitality Management, 16, 100-107.

Lawrence, J., \& Tar, U. (2010). Barriers to ecommerce in developing countries. Information Society and Justice, 3, 23-35.

Lee, M., \& Back, K. (2008). Association meeting participation: a test of competing models. Journal of Travel Research, 46, 300-310.

Litwin, M. (1995). How to measure survey reliability and validity. California, USA: SAGE publications, Inc.

MacCallum, R., \& Austin, J. (2000). Applications of structural equation modelling in psychological research. Annual Review: Psychology, 51, 201-226.

MacCallum, R., Browne, M., \& Sugawara, H. (1996). Power analysis and determination of sample size for covariance structure modeling. Psychological Methods, $1,130-149$

MacGregor, R., \& Kartiwi, M. (2010). Perception of barriers to e-commerce adoption in SMEs in a developed and developing country: a comparison between Australia and Indonesia. Journal of Electronic Commerce in Organizations, 8, $61-82$.

McAdam, R., Moffett, S., Hazlett, S., \& Shevlin, M. (2010). Developing a model of innovation implementation for UK SMEs: a path analysis and explanatory case analysis. International Small Business Journal, 28, 195-214.

Mehrtens, J., Cragg, P., \& Mills, A. (2001). A model of internet adoption by SMEs Information and Management, 39, 165-176.

Meyer, D. (2003). Outbound UK tour operator industry and implications for PPT in developing countries (Vol. 2012). PPT Partnership. PPT Working Paper No. 17.

Moore, G., \& Benbasat, I. (2001). Development of an instrument to measure the perceptions of adopting and information technology innovation. Information Systems Research, 2, 192-222.

Muthén, L., \& Muthén, B. (1998-2010). Mplus user's guide (6th ed.). Los Angeles: CA: Muthén \& Muthén.

Nemoto, M., Vasconcellos, E., \& Nelson, R. (2010). The adoption of new technology: conceptual model and application. Journal of Technology Management and Innovation, 5, 95-107.

Netemeyer, R., Bearden, W., \& Sharma, S. (2003). Scaling procedures: Issues and applications. London: Sage Publications.

Nguyen, T. H. (2009). Information technology adoption in SMEs: an integrated framework. International Journal of Enterprise Behaviour and Research, 15(2), $162-186$.

Olatokun, W., \& Kebonye, M. (2010). E-commerce technology adoption by SMEs in Botswana. International Journal of Emerging Technologies and Society, 8, 42-56.

Ongori, H. (2009). Role of information communication technologies adoption in SMEs: evidence from Botswana. Research Journal of Information Technologies, 1(2), 79-85.

Patricia, D. (2008). The internet, threat or tool for travel agencies?. Available at: http:// steconomice.uoradea.ro/anale/volume/2008/v2-economy-andbusinessadministration/017.pdf (accessed 22.12.14).

Pease, W., \& Rowe, M. (2005). An overview of information technology in the tourism industry. Available at: http://eprints.usq.edu.au/245/1/Pease.pdf (accessed: 22.12.14).

Poon, S., \& Joseph, M. (2001). A preliminary study of product nature and electronic commerce. Marketing Intelligence \& Planning, 19, 493-499.

Porter, M. (1980). Competitive strategy: Techniques for analyzing industries and competitors. New York, USA: The Free Press.

Premkumar, G., \& Roberts, M. (1999). Adoption of new information technologies in rural small businesses. Omega, International Journal of Management Science., 27, 467-484.

Quayle, M. (2002). E-commerce: the challenge for UK SMEs in the twenty-first century. International Journal of Operations \& Production Management, 22, $1148-1161$.

Raymond, L. (2001). Determinants of web site implementation in small business. Internet Research: Electronic Networking Applications and Policy, 11, 411-422.

Riemenschneider, C., Harrison, D., \& Mykytyn, P. (2003). Understanding IT adoption decision in small business: integrating current theories. Information \& Management, 40, 269-285.

Robson, C. (2002). Real world research: A resource for social scientists and practitioner-researchers (2nd ed.). Oxford, UK: Blackwell Publishers Ltd.

Rogers, E. (1995). Diffusion of innovations (4th ed.). New York: The Free Press.

Saffu, K., \& Walker, J. (2008). Strategic value and electronic commerce adoption among small and medium-sized enterprises in a transactional economy. Journal of Business \& Industrial Marketing, 23, 395-404.

Samoilenko, S., \& Osei-Bryson, K. (2008). An exploration of the effects of the interaction between E-COMMERCE and labor force on economic growth in transition economies. International Journal of Production Economics, 115, $471-481$.

Saunders, M., Thornhill, A., \& Lewis, P. (2009). Research methods for business students (5th ed.). London: Financial Times Prentice Hall.

Schermelleh-Engel, K., Moosbrugger, H., \& Müller, H. (2003). Evaluating the fit of structural equation models: tests of significance and descriptive goodness-of-fit 
measures. Methods of Psychological Research Online, 8, 23-74.

Scupola, A. (2003). The adoption of internet commerce by SMEs in the South of Italy: an environmental, technological and organizational perspective. Journal of Global Information Technology Management, 6, 52-72.

Scupola, A. (2009). SMEs' e-commerce adoption: perspectives from Denmark and Australia. Journal of Enterprise Information Management, 22, 152-166.

Sieber, S., \& Valor, J. (2008). In M. Pellicer (Ed.), Criteria for adopting information and communication technologies (2008 ed.).

Skoko, H., Ceric, A., \& Huang, C. (2008). E-COMMERCE adoption model of Chinese SMEs. International Journal of Business Research, 8, 161-165.

Stevens, J. (1996). Applied multivariate statistics for the social sciences (3rd ed.). Mahwah, New Jersey: Lawrence Erlbaum Associates.

Straub, D. W., Keil, M., \& Brenner, W. (1997). Testing the technology acceptance model across cultures: a three country study. Information and Management, 33, $1-11$.

Tan, K. S., Chong, S. C., Lin, B., \& Eze, U. C. (2009). Internet-based ICT adoption: evidence from Malaysian SMEs. Industrial Management and Data Systems, 109(2), 224-244.

Teo, T., Lin, S., \& Lai, K. (2009). Adopters and non-adopters of e-procurement in Singapore: an empirical study. Omega, 37, 972-987.

Thomas, R., Shaw, G., \& Page, S. (2011). Understanding small firms in tourism: a perspective on research trends and challenges. Tourism Management, 32, 963-976.

Thong, J. (1999). An integrated model of information systems adoption in small businesses. Journal of Management Information Systems, 15, 187-214.

Thulani, D., Tofara, C., \& Langton, R. (2010). Electronic commerce benefits and adoption barriers in small and medium enterprises in Gweru, Zimbabwe. Journal of Internet Banking and Commerce, 15, 1-17.

Tsaur, S. H., Yung, C. Y., \& Lin, J. H. (2009). The relational behavior between wholesaler and retailer travel agencies: evidence from Taiwan. Journal of Hospitality \& Tourism Research, 30(3), 333-353.

Usoro, A. (2007). E-commerce (information and communications technologies) and tourism: an initial exploratory study of developing economies as suppliers of hospitality and destination. In The 6th annual is one world conference proceedings. Las Vegas, NV.

Usoro, A., Shoyelu, S., \& Kuofie, M. (2010). Task-technology fit and technology acceptance models applicability to e-tourism. Journal of Economic Development Management IT Finance and Marketing, 2, 1-32.

Uwizeyemungu, S., \& Raymond, L. (2011). Information technology adoption and assimilation: towards a research framework for service sector SMEs. Journal of Service Science and Management, 4, 141-157.

Venkatesh, V., \& Bala, H. (2008). Technology acceptance model 3 and a research agenda on interventions. Decision Sciences, 39, 273-315.

Venkatesh, V., \& Davis, F. (2000). A theoretical extension of the technology acceptance model: four longitudinal field studies. Management Science, 46, 186-204.

Voges, K., \& Pulakanam, V. (2011). Enabling factors influencing internet adoption by New Zealand small and medium size retail enterprises. International Review of Business Research Papers, 7, 106-117.

Vrana, V., \& Zafiropoulos, C. (2006). Tourism agents' attitudes on internet adoption: an analysis from Greece. International Journal of Contemporary Hospitality Management, 18, 601-608.

Warden, S., \& Tunzelana, S. (2004). E-commerce: a critical review of SMME organisational barriers in tourism. In Proceedings of 6th WWW applications conference 2004. Johannesburg, South Africa: Rand Afrikaans University.
Zaied, A. (2012). Barriers to e-commerce adoption in Egyptian SMEs. International Journal of Information Engineering and Electronic Business, 3, 9-18.

Zheng, J., Caldwell, N., Harland, C., Powell, P., Woerndl, M., \& Xu, S. (2004). Small firms and e-business: cautiousness, contingency and cost-benefit. Journal of Purchasing \& Supply Management, 10, 27-39.

Zikmund, W. (2000). Business research methods (6th ed.). London: Harcourt College Publishers.

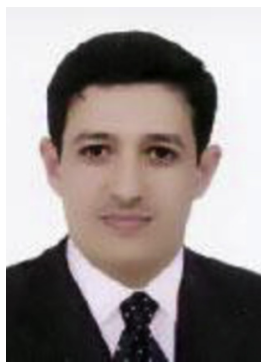

Mohamed A. Abou-Shouk holds a PhD of Tourism and Hospitality from the UK. He is a lecturer at the Faculty of Tourism and Hotels, Fayoum University, Egypt. His research interests are: Information technology and tourism, technology/ internet adoption behaviour in tourism and hospitality SMEs, e-tourism and travel agents, e-commerce and e-marketing in tourism and hospitality, and SEM-based quantitative research in tourism.

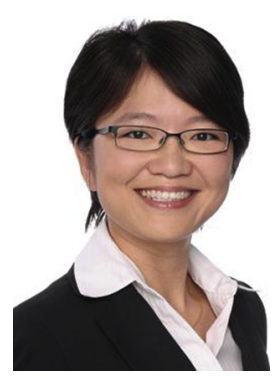

Wai Mun Lim is an Associate Professor of Service Management at the School of Tourism and Hospitality, Plymouth University, UK. Her research interests include information technology in tourism and hospitality enterprises, technology adoption behaviour, consumer behaviour in hospitality related industries and the value of collaborating with business enterprises via curriculum. She has taught e-strategies and service innovation for many years, and has published widely in tiered journals and refereed international conference proceedings.

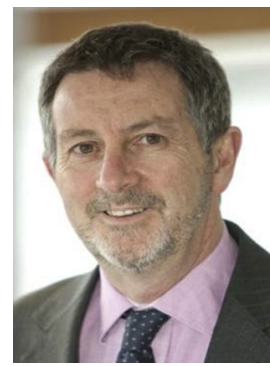

Phil Megicks is Professor of Marketing and Strategy at the University of Plymouth, UK. His research interests focus on developing and implementing strategies to support SME service industry businesses, particularly in the retail sector; ethical consumer behaviour in relation to shopping with specific emphasis on food buying; and establishing effective supply chain management practices and E-Commerce adoption in SMEs. His work has been published in a range of journals including the European Journal of Marketing, the Journal of Business Research, the Journal of Marketing Management and the Service Industries Journal. He has for many years taught marketing to students and professionals, and advised small service businesses on the implementation of marketing planning to improve performance. 